\title{
Carbamazepine Induced Ebstein-Barr Virus Reactivation: A Rare Manifestation of Anticonvulsant Hypersensitivity Syndrome
}

\author{
Yildiz Degirmenci ${ }^{*}$, Hulusi Kececi ${ }^{1}$, Emel Çalişkan² \\ ${ }^{1}$ Neurology Department, Duzce University School of Medicine, Duzce, Turkey \\ ${ }^{2}$ Medical Microbiology Department, Duzce University School of Medicine, Duzce, Turkey \\ Email: “ydegir@gmail.com, hulusikececi@hotmail.com, emelcaliskan81@yahoo.com.tr
}

Received 18 March 2016; accepted 24 May 2016; published 27 May 2016

Copyright (C) 2016 by authors and Scientific Research Publishing Inc.

This work is licensed under the Creative Commons Attribution International License (CC BY). http://creativecommons.org/licenses/by/4.0/

(c) (i) Open Access

\begin{abstract}
Carbamazepine (CBZ) is an antiepileptic drug which has multiple mechanisms of action including stabilization of the inactivated stage of the voltage-gated sodium channels, potentiating gamma-amino butyric acid (GABA) receptors as a GABA antagonist, as well as the serotonin releasing affect. It is effective in neuropathic pain syndromes such as post-herpetic neuralgia and trigeminal neuralgia, as well as epilepsy. We presented a 29-year-old female patient with the diagnosis of trigeminal neuralgia (TN) who experienced a reactivation of the latent Ebstein-Barr Virus (EBV) infection in terms of anticonvulsant hypersensitivity syndrome after CBZ use, who gave her approval to publish her data. Since the clinical and serological findings of EBV re-infection resolved after the discontinuation of the drug, this clinical and serological manifestation was attributed to CBZ. Since common side-effects of CBZ are drowsiness, dizziness, headaches, skin reactions, cognitive dysfunctions, we reported an activation of EBV infection due to CBZ consumption as a rare side-effect of the drug.
\end{abstract}

\section{Keywords}

Carbamazepine, Anticonvulsant Hypersensitivity Syndrome, Ebstein-Barr Virus Infection

\section{Introduction}

Carbamazepine is a well-known antiepileptic drug which has multiple mechanisms of action including stabilization of the inactivated stage of the voltage-gated sodium channels, potentiating GABA receptors as a GABA an-

\footnotetext{
${ }^{*}$ Corresponding author.
}

How to cite this paper: Degirmenci, Y., Kececi, H. and Çalişkan, E. (2016) Carbamazepine Induced Ebstein-Barr Virus Reactivation: A Rare Manifestation of Anticonvulsant Hypersensitivity Syndrome. Neuroscience \& Medicine, 7, 45-48. 
tagonist, as well as the serotonin releasing affect [1]-[3]. Due to these different mechanisms of action, CBZ is found to be effective in bipolar disorders, neuropathic pain of various kinds, as well as epilepsy [4]. CBZ is one of the first line treatment options in neuropathic pain syndromes such as post-herpetic neuralgia and TN [5]. Meanwhile, voltage-gated sodium channel blockage seems to be the major mechanism of action leading to pain relief in these syndromes by reducing the frequency of sustained repetitive firing of action potential in neurons $[6]$.

As a frequently used AED, the most common side-effects of CBZ can be summarized as drowsiness, dizziness, headaches, skin reactions, cognitive dysfunctions including memory and concentration problems. Less common but more serious side-effects are increased suicide risk, blurry or double vision, agranulocytosis, aplastic anemia and anticonvulsant hypersensitivity syndrome (AHS) [7] [8]. As we know from the literature, AHS is a rare, life-threatening condition most likely to occur with aromatic AEDs like phenytoin, phenobarbital, and CBZ [9]. But the rarest form of AHS is the one leading to the reactivation of viral infections including Herpes simplex virus, varicella zoster virus, human herpes virus-6, cytomegalovirus and EBV which are limited to a few reports [10] [11]. According to our knowledge and literature review, our case is the third report with AHS leading to EBV reactivation due to CBZ. Thus we shared this unique case of TN who experienced reactivation of EBV infection due to CBZ as a result of AHS to keep in mind this rare but important side-effect of the drug.

\section{Case-Report}

A 29-year-old, right handed woman admitted to our outpatient neurology clinic with unilateral headache complaint in the second and third divisions of the trigeminal nerve. Pain was paroxysmal with attacks lasting seconds to minutes with an electric shock-like character. Pain had trigger points which were activating by touch to her cheek. Her systemic and neurological examination was normal. Routine blood tests including complete blood count, erythrocyte sedimentation rate, serum kidney and liver function tests, electrolytes, fasting blood glucose, and thyroid functions were normal. Since the type of headache was consistent with trigeminal neuralgia according to the criteria of international headache society (IHS) classification 3rd edition beta-3 version, CBZ was administered to the patient and gradually increased to 200 milligram of twice daily [12]. One week after CBZ regimen, the patient was pain-free. At the 10th day, mild rash appeared on her chest without pruritus and she had no fever either. Her general physical examination revealed lymphadenopathy in the inguinal region with mild pain. Routine laboratory investigations revealed normal white blood count, with normal liver and kidney function tests. Serum bilirubin and alkaline phosphatase, and $\gamma$ GTP levels and thyroid function tests were also normal. Urinary analysis showed normal results. Total serum immunoglobulin (Ig) E level was found to be increased $(125,4 \mathrm{IU} / \mathrm{milliliters,} \mathrm{range}=0-100 \mathrm{IU} / \mathrm{mL})$. Serological tests were performed to investigate viral origin. The evaluation with indirect immune fluorescence assay (Euuroimmune, Germany) revealed negative anti-EBV early antigen (EA), but positive anti-EBV nuclear antigen IgG antibody in the serum. Moreover, there was positivity in EBV viral capsid antigene (VCA) IgM titers.

Other serological tests were performed to exclude viral and autoimmune hepatitis. Positivity of anti-hepatitis Bs (HBs) antibody, and increased anti-hepatitis A virus (HAV) IgG antibody with $>100.0 \mathrm{~S} / \mathrm{CO}$ was consistent with previous hepatitis B virus (HBV) and HAV infections. Tests for autoimmune markers demonstrated a weak positive antinuclear antigen (ANA) with granular pattern. Serum anti-CMV IgG, anti-Rubella IgG, and antitoxoplasma IgG titers were positive. There were atypical lymphocytes defined as Downey cells in the peripheral blood smear of the patient (Figure 1).

As we detailed the medical history of the patient, we learned that she had a history of EBV infection 5 years ago. Regarding the medical history and laboratory findings consistent with prior EBV infection, and present clinical findings, the patient was diagnosed as the reactivation of the latent EBV infection. Since the only trigger for reactivation was AED use, the clinical manifestation was attributed to AHS due to CBZ. Based on the diagnosis, CBZ was switched to pregabaline which is another effective AED in TN. Skin eruptions resolved within 2 days of withdrawal. Lymphadenopathy disappeared within 15 days, and serological abnormalities returned to normal in 3 weeks.

\section{Discussion}

$\mathrm{TN}$ is a severe neuropathic pain in the distribution of one or more branches of the trigeminal nerve, which is characterized by short-lasting, recurrent episodes of electrical and/or shock-like pain with abrupt onset and ter- 


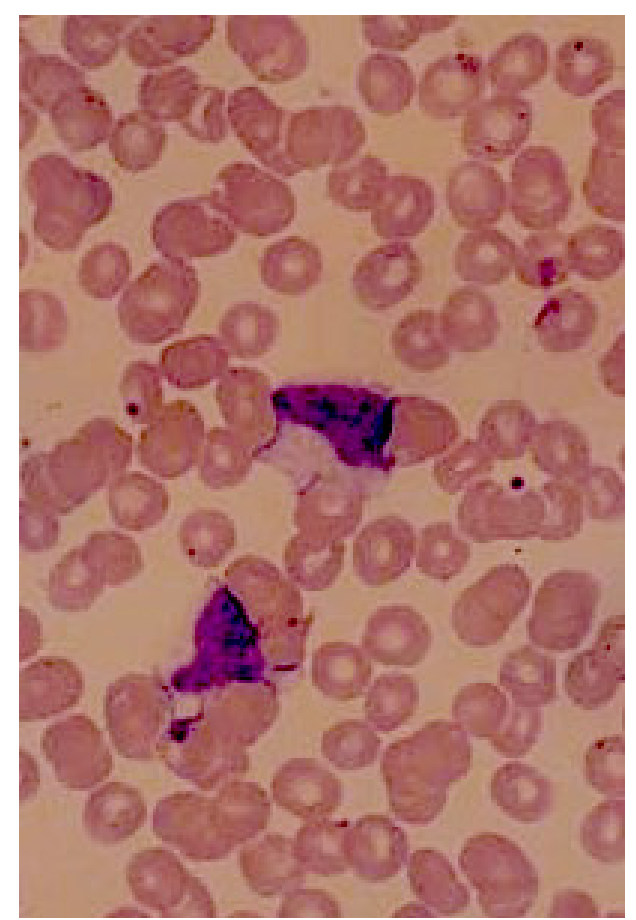

Figure 1. Peripheral blood smear; atypical lymphocytes defined as Downey cells.

mination [12]. Since it is a disabling neuralgiform pain disorder, the underlying pathophysiology is considered to be the sensitization of trigeminal nociceptive systems in the brain [13]. As one of the first-line treatment options, CBZ is thought to work by blocking voltage-sensitive sodium channels which makes brain cells less excitable and relief the pain in TN [14].

The most common side-effects of CBZ are skin reactions, headache, drowsiness, blurred vision, nausea and vomiting, etc. [7]. We here presented an AHS leading to the reactivation of EBV as a rare side effect of CBZ. Serological diagnosis of EBV reactivation can be made by the positivity of ebstein-barr nuclear antigen (EBNA), EA, VCA IgG. VCA IgM can be positive or negative [15]. Since the indirect immune fluorescence assay results revealed positive EBNA IgG and VCA IgM titers, our patient was diagnosed as the reactivation of EBV infection. To our knowledge, there is limited number of reports revealing EBV, HHV-6, HHV-7 infection due to AEDs in terms of anticonvulsant hypersensitivity syndrome (AHS) [10] [11]. AHS can be defined as a serious condition that presents with systemic clinical involvement as fever, rash, lymphadenopathy, and hematological abnormalities including leukocytosis, eosinophilia or atypical lymphocytosis which commonly occurs with AEDs such as CBZ, phenytoin, and Phenobarbital [16]. Since our patient experienced mild rash and inguinal lymphadenopathy 10 days after CBZ treatment, and serological findings were consistent with EBV reactivation, and resolved with the discontinuation of the drug, this clinical features were attributed to CBZ induced AHS presented as EBV reactivation. However, the exact role of EBV in the pathophysiological mechanisms of AHS is not clear. One possible way of CBZ to trigger immune response leading to the development of AHS may be the decreased B-cell count and immunoglobulin production in susceptible individuals, resulting in reactivation of viral infections [17].

\section{Conclusion}

Since carbamazepine is frequently used AED in the treatment of various conditions including epilepsy, neuralgiform disorders as TN, and many others, it is important to question the history of EBV and other viral infections in patients in order to prevent recurrent infections in terms of AHS which can be a life-threatening condition.

\section{Acknowledgements}

There is no funding or support. 


\section{Conflicts of Interest}

There are no conflicts of interest reported by the authors.

\section{References}

[1] Dailey, J.W., Reith, M.E., Steidley. K.R., Milbrandt, J.C. and Jobe, P.C. (1998) Carbamazepine-Induced Release of Serotonin from Rat Hippocampus in Vitro. Epilepsia, 39, 1054-1063. http://dx.doi.org/10.1111/j.1528-1157.1998.tb01290.x

[2] Dailey, J.W., Reith, M.E., Yan, Q.S., Li, M.Y. and Jobe, P.C. (1997) Carbamazepine Increases Extracellular Serotonin Concentration: Lack of Antagonism by Tetrodotoxin or Zero $\mathrm{Ca}^{2+}$. European Journal of Pharmacology, 328, 153-162. http://dx.doi.org/10.1016/S0014-2999(97)83041-5

[3] Kawata, Y., Okada, M., Murakami, T., Kamata, A., Zhu, G. and Kaneko, S. (2001) Pharmacological Discrimination between Effects of Carbamazepine on Hippocampal Basal Evoked Serotonin Release. British Journal of Pharmacology, 133, 557-567. http://dx.doi.org/10.1038/sj.bjp.0704104

[4] Bialer, M. (2012) Why Are Antiepileptic Drugs Used for Nonepileptic Conditions? Epilepsia, 53, 26-33. http://dx.doi.org/10.1111/j.1528-1167.2012.03712.x

[5] Goodyear-Smith, F. and Halliwell, J. (2009) Anticonvulsants for Neuropathic Pain: Gaps in the Evidence. Clinical Journal of Pain, 25, 528-536. http://dx.doi.org/10.1097/AJP.0b013e318197d4cc

[6] Spina, E. and Perugi, G. (2004) Antiepileptic Drugs: Indications Other than Epilepsy. Epileptic Disorders, 6, 57-75.

[7] Besi, E., Boniface, D.R., Cregg, R. and Zakrzewska, J.M. (2015) Comparison of Tolerability and Adverse Symptoms in Oxcarbazepine and Carbamazepine in the Treatment of Trigeminal Neuralgia and Neuralgiform Headaches Using the Liverpool Adverse Events Profile (AEP). The Journal of Headache and Pain, 16, 563. http://dx.doi.org/10.1186/s10194-015-0563-Z

[8] Handoko, K.B., Souverein, P.C., van Staa, T.P., Meyboom, R.H., Leufkens, H.G., Egberts, T.C. and van den Bemt, P.M. (2006) Risk of Aplastic Anemia in Patients Using Antiepileptic Drugs. Epilepsia, 47, 1232-1236. http://dx.doi.org/10.1111/j.1528-1167.2006.00596.x

[9] Kumari, R., Timshina, D.K. and Thappa, D.M. (2011) Drug Hypersensitivity Syndrome. Indian Journal of Dermatology, Venereology and Leprology, 77, 7-15. http://dx.doi.org/10.4103/0378-6323.74964

[10] Chang, J.Y. and Kim, S.C. (2007) Anticonvulsant Hypersensitivity Syndrome Associated with Epstein-Barr Virus Reactivation. Yonsei Medical Journal, 48, 317-320. http://dx.doi.org/10.3349/ymj.2007.48.2.317

[11] Oskay, T., Karademir, A. and Ertürk, O.I. (2006) Association of Anticonvulsant Hypersensitivity Syndrome with Herpesvirus 6, 7. Epilepsy Research, 70, 27-40. http://dx.doi.org/10.1016/j.eplepsyres.2006.02.006

[12] Oomens, M.A. and Forouzanfar, T. (2015) Pharmaceutical Management of Trigeminal Neuralgia in the Elderly. Drugs Aging, 32, 717-726. http://dx.doi.org/10.1007/s40266-015-0293-6

[13] Joffroy, A., Levivier, M. and Massager, N. (2001) Trigeminal Neuralgia. Pathophysiology and Treatment. Acta Neurologica Belgica, 101, 20-25.

[14] Wiffen, P.J., Derry, S., Moore, R.A. and McQuay, H.J. (2011) Carbamazepine for Acute and Chronic Pain in Adults. Cochrane Database of Systematic Reviews, 1, Article ID: CD005451. http://dx.doi.org/10.1002/14651858.CD005451.pub2

[15] Fidan, I., Yüksel, S. and İmir, T. (2005) The Investigation of Epstein-Barr Virus Antibodies in Different Age Groups. Turkish Journal of Infection, 19, 453-456.

[16] Sullivan, J.R. and Shear, N.H. (2001) The Drug Hypersensitivity Syndrome: What Is the Pathogenesis? Archives of Dermatology, 137, 357-364.

[17] Kano, Y., Inaoka, M. and Shiohara, T. (2004) Association between Anticonvulsant Hypersensitivity Syndrome and Human Herpesvirus 6 Reactivation and Hypogammaglobulinemia. Archives of Dermatology, 140, 183-188. http://dx.doi.org/10.1001/archderm.140.2.183 